\title{
Association Between Walking and Low Back Pain in the Korean Population: A Cross-Sectional Study
}

\author{
Heesang Kim, MD ${ }^{1}$, Tae Jun Min, $\mathrm{MD}^{1}$, Si Hyun Kang, MD, PhD ${ }^{1}$, Don-Kyu Kim, MD, PhD ${ }^{1}$, \\ Kyung Mook Seo, $\mathrm{MD}, \mathrm{PhD}^{1}$, Sang Yoon Lee, $\mathrm{MD}, \mathrm{PhD}^{2}$ \\ ${ }^{1}$ Department of Physical Medicine and Rehabilitation, Chung-Ang University Hospital, Seoul; \\ ${ }^{2}$ Department of Rehabilitation Medicine, Seoul National University Boramae Medical Center, Seoul, Korea
}

Objective To investigate if walking is independently associated with low back pain (LBP) in the general population.

Methods This cross-sectional study used public data from the Fourth and Fifth Korean National Health and Nutrition Examination Survey. Subjects included 5,982 community-dwelling adults aged $\geq 50$ years. Presence of current LBP was defined as LBP for 1 month or more in the past 3 months. Walking was measured as total walking duration for the past week and subjects were divided into four quartiles. Independent effect of walking on LBP was determined using odds ratios (OR) adjusted for age, sex, osteoporosis, depression or anxiety, and radiographic lumbar spondylosis.

Results Prevalence of LBP was $26.4 \%$ in this population. Older people and women had higher prevalence of current LBP. Prevalence of obesity and osteoporosis was higher in subjects with current LBP and quality of life was poorer in subjects with current LBP. Adjusted logistic regression model revealed that older age (OR, 1.655; $\mathrm{p}=0.018)$, female sex $(\mathrm{OR}, 2.578 ; \mathrm{p}<0.001)$, radiographic lumbar spondylosis $(\mathrm{OR}, 2.728 ; \mathrm{p}<0.001)$, depression or anxiety (OR, 5.409; $\mathrm{p}<0.001)$, and presence of osteoporosis $(\mathrm{OR}, 1.467 ; \mathrm{p}=0.002)$ were positively associated with current LBP. Walking decreased prevalence of current LBP proportionally (2nd quartile OR, 0.795; 3rd quartile OR, 0.770 ; and 4th quartile OR, 0.686 compared with the 1st quartile of walking).

Conclusion Walking was negatively associated with LBP. Further studies are needed to reveal causal relationship of this phenomenon.

Keywords Low back pain, Spondylosis, Walking, Exercise, Cross-sectional studies

Received January 11, 2017; Accepted March 27, 2017

Corresponding author: Sang Yoon Lee

Department of Rehabilitation Medicine, Seoul National University Boramae Medical Center, 20 Boramae-ro 5-gil, Dongjak-gu, Seoul 07061, Korea. Tel: +82-2-870-2673, Fax: +82-2-831-0714, E-mail: rehabilee@gmail.com

ORCID: Heesang Kim (http://orcid.org/0000-0002-8759-1725); Tae Jun Min (http://orcid.org/0000-0002-9976-3053); Si Hyun Kang (http://orcid. org/0000-0003-0205-067X); Don-Kyu Kim (http://orcid.org/0000-0001-8619-830X); Kyung Mook Seo (http://orcid.org/0000-0002-9762-085X); Sang Yoon Lee (http://orcid.org/0000-0002-2906-3094).

() This is an open-access article distributed under the terms of the Creative Commons Attribution Non-Commercial License (http://creativecommons.org/ licenses/by-nc/4.0) which permits unrestricted noncommercial use, distribution, and reproduction in any medium, provided the original work is properly cited. Copyright $\odot 2017$ by Korean Academy of Rehabilitation Medicine 


\section{INTRODUCTION}

Physical inactivity or a sedentary lifestyle has been linked to several musculoskeletal issues [1,2]. It may be a risk factor for development of chronic pain [3]. In several cross-sectional studies, physical inactivity was associated with high prevalence of musculoskeletal pain [46]. Regular physical activity is a protective factor against many musculoskeletal diseases. A 1-year prospective cohort study suggested that increasing the number of steps walked daily is a protective factor against neck pain in a sedentary population [7]. A 14-year prospective longitudinal study reported that long-term aerobic exercise was associated with reducing musculoskeletal pain compared to sedentary controls [8].

Walking is the most common aerobic exercise and has been advocated by public health initiatives [9]. Walking may prevent several chronic medical issues $[10,11]$, and walking speed is associated with survival in older adults [12]. A study suggested that a timed usual gait provides predictive value for disability onset [13]. Walking 4-5 $\mathrm{km}$ daily improves mood, quality of life, self-confidence and reduces metabolic risk [14]. The European Working Group on Sarcopenia recommended that walking speed be used to measure individual performance for clinical practice and research [15]. As walking is an accessible aerobic exercise, it may be recommended by healthcare professionals to subjects, including the elderly.

Low back pain (LBP) is the most prevalent musculoskeletal issue that may affect one's lifestyle [16]. It is a major burden on public health [17]. Lifetime prevalence of LBP is as high as $84 \%$, while prevalence of chronic LBP is approximately $23 \%[18,19]$. Although a recent clinical guideline suggested that patients with chronic LBP should be prescribed exercise therapy [20], few studies have identified which exercises are more effective [21] and association between walking and LBP has not been fully investigated. In our study, we focused on investigating if walking is independently associated with LBP in the population. We hypothesized that walking may be negatively correlated with presence of LBP.

\section{MATERIALS AND METHODS}

\section{Study population}

This cross-sectional study used public data of 17,476 community-dwelling people from the V-1 and V-2 Korean National Health and Nutrition Examination Survey (KNHANES) from 2010-2011. We analyzed target subjects age $\geq 50$ that completed surveys on height, weight, waist circumference, presence of LBP, International Physical Activity Questionnaire (IPAQ) with examinations of dualenergy X-ray absorptiometry (DEXA) and plain radiography of the lumbar spine. All subjects were divided into four age subgroups: $<60,60-69,70-79$, and $\geq 80$. A total of 5,982 subjects completed surveys and were included in this study. This study is an analysis of public data from the KNHANES and ethical approval was not required.

\section{LBP and spine radiography}

Presence of LBP was identified by asking participants if they had experienced LBP for 1 month or more during the last three months. According to responses, subjects were separated into LBP and control groups. Plain radiographies of the lumbar spine were conducted in weightbearing anteroposterior and lateral views. Radiographic findings were rated using the Kellgren/Lawrence grading system by two musculoskeletal radiologists with concordant grades accepted as follows: $0=$ normal; $1=$ definite osteophyte; and 2=intervertebral disc space narrowing, bone sclerosis, and large osteophytes. If there was a difference of 1 grade between the two radiologists' assessments, the higher grade was accepted [22].

\section{Obesity and bone mineral density}

Body mass index (BMI) was calculated as the individual's body mass divided by the square of one's height $\left(\mathrm{kg} / \mathrm{m}^{2}\right)$. Low body weight was defined as a BMI $<18.5 \mathrm{~kg} /$ $\mathrm{m}^{2}$ and the cut-off value of obesity was a BMI $\geq 25 \mathrm{~kg} / \mathrm{m}^{2}$ [23]. Bone mineral density (BMD) in the lumbar spine was measured by DEXA (DISCOVERY-W fan-beam densitometer; Hologic Inc., Bedford, MA, USA) using standard procedures. Osteoporosis and osteopenia were defined as a T-score $<-2.5$ and a T-score between -2.5 and -1.0 , respectively.

\section{Walking measurements}

The short version of the IPAQ in Korea [24], measuring health-related physical activity in populations, was used to measure subjects' current walking. Number of days the subject walked $\geq 10$ minutes at a time for the last 1 week was expressed. Walking was measured by total walking 
time in a week (TWT), calculated as follows:

$$
\begin{aligned}
& \text { TWT= } \\
& \text { walking days (days/week) } \times \\
& \text { walking minutes (minutes/day). }
\end{aligned}
$$

Based on the TWT, subjects were divided into TWT quartiles.

\section{Depression or anxiety}

Degrees of depression or anxiety were assessed from the EQ-5D descriptive system [25], describing health status according to the following five dimensions: mobility, self-care, usual activities, pain or discomfort, and anxiety or depression. Each dimension has three levels: no issues, some issues, and extreme issues. Depression/anxiety were divided into three subgroups. EQ-visual analog scale (VAS) records an individual's self-rated health on a VAS. Respondents recorded their health status from 0 (worst imaginable health) to 100 (best imaginable health) [26].

\section{Statistical analysis}

Independent t-tests were used to compare age, anthropometric data, BMD of the lumbar spine, and TWT between LBP and control groups. Comparisons of sex ratio and the prevalence of obesity and osteoporosis between groups were conducted using the chi-square test. Independent effects of walking on LBP were determined using multivariate logistic regression models unadjusted and adjusted for the following five potential prognostic factors: age, sex, osteoporosis, depressive mood, and radiographic lumbar spondylosis. The adjusted model was developed through backward elimination with significance level of 0.2 to enter and 0.05 to stay. The authors evaluated possible multiple collinearities between covariates by correlation analysis and collinearity statistical tests (tolerance and variance inflation factor tests) as suggested for regression analysis. PASW Statistics ver. 18 (SPSS Inc., Chicago, IL, USA) was used for the analyses. A p-value $<0.05$ was considered significant.

\section{RESULTS}

\section{Subjects' characteristics}

Subjects' clinical characteristics according to presence or absence of LBP are shown in Table 1. Of 5,982 subjects, 1,577 (26.4\%) had current LBP. Subjects with current LBP had higher mean age $(66.9 \pm 9.4$ vs. $62.8 \pm 8.9 ; \mathrm{p}<0.001)$ and male to female ratio $(\mathrm{p}<0.001)$ than those in the control group. While BMI did not differ between groups, prevalence of obesity ( $37.3 \%$ vs. $34.5 \%$; $\mathrm{p}=0.043$ ) and osteoporosis $(28.5 \%$ vs. $15.4 \%$; $\mathrm{p}<0.001)$ were higher in the LBP group. The LBP group revealed significantly lower EQVAS ( $61.3 \pm 22.0$ vs. $73.3 \pm 18.7 \mathrm{~mm}$; $\mathrm{p}<0.001$ ), number of walking days ( $4.6 \pm 2.9$ vs. $4.9 \pm 2.7$ days/week; $\mathrm{p}=0.001$ ), and TWT (240.3 \pm 361.1 vs. $303.0 \pm 408.0$ minutes/week) than the control group, respectively.

\begin{tabular}{|c|c|c|c|}
\hline & Control $(n=4,405)$ & Back pain $(n=1,577)$ & p-value* \\
\hline Age (yr) & $62.8 \pm 8.9$ & $66.9 \pm 9.4$ & $<0.001$ \\
\hline Sex & & & $<0.001$ \\
\hline Men & 2,193 & 2,212 & \\
\hline Women & 393 & 1,184 & \\
\hline $\operatorname{BMI}\left(\mathrm{kg} / \mathrm{m}^{2}\right)$ & $23.9 \pm 3.0$ & $24.1 \pm 3.4$ & 0.067 \\
\hline Obesity (\%) & 34.5 & 37.3 & $0.043^{* *}$ \\
\hline BMD of the lumbar spine $\left(\mathrm{g} / \mathrm{cm}^{2}\right)$ & $0.89 \pm 0.16$ & $0.82 \pm 0.17$ & $<0.001$ \\
\hline Osteoporosis, lumbar spine (\%) & 15.4 & 28.5 & $<0.001$ \\
\hline EQ-VAS (mm) & $73.3 \pm 18.7$ & $61.3 \pm 22.0$ & $<0.001$ \\
\hline Walking days (per week) & $4.9 \pm 2.7$ & $4.6 \pm 2.9$ & 0.001 \\
\hline Total walking time (min/wk) & $303.0 \pm 408.0$ & $240.3 \pm 361.1$ & $<0.001$ \\
\hline
\end{tabular}

Table 1. Subjects' characteristics by study group

Values are presented as mean \pm standard deviation or number of patients. BMI, body mass index; BMD, bone mineral density; VAS, visual analog scale. *Independent t-test, ${ }^{* *}$ chi-square test for group differences. 


\section{Independent effects of walking on LBP}

By the unadjusted analysis, women had a higher odds ratio (OR) of having LBP than men (unadjusted OR, 2.987; 95\% CI, 2.627-3.396; $\mathrm{p}<0.001$ ). Subjects $>$ age 80 had significantly higher OR than those <age 60 (unadjusted OR, 3.930; 95\% CI, 3.067-5.037; $\mathrm{p}<0.001$ ). Osteoporosis, depression/anxiety, and radiographic spondylosis were positively correlated with current LBP. The more subjects walked, the lower OR revealed proportionally (2nd quartile OR, 0.693; 3rd quartile OR, 0.655; and 4th quartile OR, 0.544 compared with the 1st quartile). However, obesity did not have significant OR of LBP. When obesity was excluded in the final adjusted model, older age, female sex, osteoporosis, depression/anxiety, and radiographic spondylosis revealed significant correlation with LBP. Walking was also negatively correlated to presence of current LBP (2nd quartile OR, 0.795; 3rd quartile OR, 0.770 ; and 4th quartile OR, 0.686 compared with the 1st

Table 2. Unadjusted and adjusted odds ratios of current low back pain

\begin{tabular}{|c|c|c|c|c|c|}
\hline & $\begin{array}{c}\text { No. of } \\
\text { patients }\end{array}$ & $\begin{array}{c}\left.\text { Unadjusted } O^{a}{ }^{a}\right) \\
(95 \% \text { CI })\end{array}$ & p-value & $\begin{array}{l}\text { Adjusted OR }{ }^{\mathrm{b})} \\
(95 \% \mathrm{CI})\end{array}$ & p-value \\
\hline \multicolumn{6}{|l|}{ Sex } \\
\hline Male & 1,592 & 1.000 & & 1.000 & \\
\hline Female & 1,875 & $2.987(2.627-3.396)$ & $<0.001$ & $2.578(2.136-3.112)$ & $<0.001$ \\
\hline \multicolumn{6}{|l|}{ Age (yr) } \\
\hline$<60$ & 1,299 & 1.000 & & 1.000 & \\
\hline $60-69$ & 1,233 & $1.704(1.470-1.974)$ & $<0.001$ & $1.465(1.188-1.806)$ & $<0.001$ \\
\hline $70-79$ & 795 & $2.561(2.198-2.984)$ & $<0.001$ & $1.693(1.332-2.152)$ & $<0.001$ \\
\hline$\geq 80$ & 140 & $3.930(3.067-5.037)$ & $<0.001$ & 1.655 (1.091-2.512) & 0.018 \\
\hline Obesity & & & & \multicolumn{2}{|c|}{ Not included in the final adjusted mode } \\
\hline Low weight & 94 & 1.000 & & & \\
\hline Normal & 2,154 & $0.749(0.542-1.036)$ & 0.081 & & \\
\hline Obese & 1,219 & $0.860(0.618-1.195)$ & 0.369 & & \\
\hline \multicolumn{6}{|l|}{ Osteoporosis } \\
\hline Normal & 1,392 & 1.000 & & 1.000 & \\
\hline Osteopenia & 1,428 & $1.589(1.329-1.900)$ & $<0.001$ & $1.205(0.989-1.468)$ & 0.064 \\
\hline Osteoporosis & 647 & $2.820(2.293-3.468)$ & $<0.001$ & $1.467(1.148-1.875)$ & 0.002 \\
\hline \multicolumn{6}{|c|}{ Depression or anxiety } \\
\hline None & 3,005 & 1.000 & & 1.000 & \\
\hline Some & 414 & $2.948(2.526-3.439)$ & $<0.001$ & $2.521(2.012-3.160)$ & $<0.001$ \\
\hline Extreme & 48 & $6.717(4.206-10.725)$ & $<0.001$ & $5.409(2.858-10.238)$ & $<0.001$ \\
\hline \multicolumn{6}{|c|}{ Radiographic spondylosis } \\
\hline K-L grade 0 & 595 & 1.000 & & 1.000 & \\
\hline K-L grade 1 & 1,791 & $1.616(1.347-1.939)$ & $<0.001$ & $1.586(1.212-2.076)$ & 0.001 \\
\hline$K$-L grade $\geq 2$ & 1,081 & $3.473(2.895-4.167)$ & $<0.001$ & $2.728(2.044-3.640)$ & $<0.001$ \\
\hline \multicolumn{6}{|l|}{ Walking } \\
\hline $1 \mathrm{Q}$ & 802 & 1.000 & & 1.000 & \\
\hline $2 \mathrm{Q}$ & 901 & $0.693(0.591-0.813)$ & $<0.001$ & $0.795(0.633-0.999)$ & 0.049 \\
\hline $3 \mathrm{Q}$ & 871 & $0.655(0.558-0.769)$ & $<0.001$ & $0.770(0.612-0.970)$ & 0.027 \\
\hline $4 \mathrm{Q}$ & 893 & $0.544(0.461-0.642)$ & $<0.001$ & $0.686(0.542-0.869)$ & 0.002 \\
\hline
\end{tabular}

OR, odds ratio; CI, confidence interval; K-L, Kellgren-Lawrence; Q, quartile.

${ }^{a)}$ Unadjusted ORs by logistic regression analysis

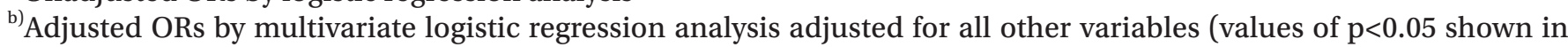
bold text). 
quartile) (Table 2).

\section{DISCUSSION}

The most important findings of this study were that prevalence of current LBP was $26.4 \%$ and subjects with current LBP were more likely to be older, obese, and osteoporotic than the control group. The LBP group had lower quality of life and engaged less in walking. Although BMI, obesity did not correlate with current LBP, older age, female sex, osteoporosis, depression or anxiety, radiographic degeneration, and less walking were significantly associated with it.

A few studies have insisted on limitations of excessive physical activity. Shiri et al. [27] proposed a U-shaped correlation between physical activity and radiating LBP. The authors suggested that high level of physical activity may increase the risk of radiating LBP, while moderate level of physical activity is recommended to prevent LBP. A cross-sectional study using KNHANES data reported that physical activity quartiles had U-shaped association with LBP in men [6]. Conflicting evidence about the relationship between physical activity and musculoskeletal pain may relate to heterogeneity in methods of assessing physical activity among studies [28]. In the two mentioned studies [6,27], the authors calculated physical activity using a combination of all physical activity types, ranging from leisurely to vigorous. The effects of walking alone could not be identified in these studies.

A prospective cohort study reported no significant association between daily walking and onset of LBP [7]. However, in this study, participants were workers with sedentary jobs, not a general population. Poor repeatability of daily walking outcome was revealed when weekend data were used (intra-class correlation coefficient, 0.17). Inconsistent activity recording may be accountable for fair repeatability of daily walking step outcomes. Hendrick et al. [29] revealed no positive effect of free-living walking to manage LBP and treadmill walking as management for LBP also revealed poor evidence from a systematic review. They suggested that it would be 'prudent' to recommend patients with LBP to encourage walking as an important treatment option. However, as they noted, a small sample size and poor methodological quality of target studies in the review may considerably weaken the effect of walking.
In our study, walking was associated with reduced risk of LBP. The association may be significantly independent because potential covariates were assessed using a logistic regression model. These findings are consistent with results of previous studies. Sculco et al. [30] conducted a case-control study and reported that low to moderate aerobic exercise including walking improves LBP and reduces need for physical therapy referrals and pain medication. A randomized controlled trial suggested that a pedometer-based 6 month-walking intervention revealed significant effect on back pain related disability [31]. The authors reported that Internet-mediated intervention may be effective in promoting a more rapid reduction in back pain related disability for chronic LBP patients. Torstensen et al. [32] revealed that a 12-week intervention with free-living walking (for 1 hour three times a week) reduced back pain. Therefore, regular walking may facilitate control and prevent development of LBP.

This study had several limitations. First, it was difficult to establish causal relationship between LBP and walking because of limitations of cross-sectional studies. It cannot be understated that subjects with current LBP have walked less frequently. Gait coordination is changed in patients with LBP [33] and they usually walk slower than the healthy population [34]. It is impossible to discriminate if subjects with LBP do less walking or walking had the protective effect of LBP. Second, information was obtained through self-reporting; therefore, self-selection and recall biases may have occurred. Third, although we categorized walking according to total exercise, we did not investigate other characteristics of walking such as intensity (speed), occupation, or leisure time. Therefore, further studies with long-term cohorts are required to investigate effectiveness of walking for LBP treatment to clarify results.

Walking was negatively associated with presence of LBP proportionate to walking frequency. This is the first clinical report to imply that LBP may be independently influenced by walking. Further longitudinal studies or controlled trials are needed to reveal causal relationship of this phenomenon.

\section{CONFLICT OF INTEREST}

No potential conflict of interest relevant to this article is reported. 


\section{ACKNOWLEDGMENTS}

The Korea National Health and Nutrition Examination Survey (KNHANES) is financially supported by the Health Promotion Fund with administrative support by the Ministry of Health and Welfare.

\section{REFERENCES}

1. Holth HS, Werpen HK, Zwart JA, Hagen K. Physical inactivity is associated with chronic musculoskeletal complaints 11 years later: results from the NordTrøndelag Health Study. BMC Musculoskelet Disord 2008;9:159.

2. Hildebrandt VH, Bongers PM, Dul J, van Dijk FJ, Kemper HC. The relationship between leisure time, physical activities and musculoskeletal symptoms and disability in worker populations. Int Arch Occup Environ Health 2000;73:507-18.

3. Sluka KA, O'Donnell JM, Danielson J, Rasmussen LA. Regular physical activity prevents development of chronic pain and activation of central neurons. J Appl Physiol (1985) 2013;114:725-33.

4. Bo Andersen L, Wedderkopp N, Leboeuf-Yde C. Association between back pain and physical fitness in adolescents. Spine (Phila Pa 1976) 2006;31:1740-4.

5. Morken T, Mageroy N, Moen BE. Physical activity is associated with a low prevalence of musculoskeletal disorders in the Royal Norwegian Navy: a cross sectional study. BMC Musculoskelet Disord 2007;8:56.

6. Kim W, Jin YS, Lee CS, Hwang CJ, Lee SY, Chung SG, et al. Relationship between the type and amount of physical activity and low back pain in Koreans aged 50 years and older. PM R 2014;6:893-9.

7. Sitthipornvorakul E, Janwantanakul P, Lohsoonthorn V. The effect of daily walking steps on preventing neck and low back pain in sedentary workers: a 1-year prospective cohort study. Eur Spine J 2015;24:417-24.

8. Bruce B, Fries JF, Lubeck DP. Aerobic exercise and its impact on musculoskeletal pain in older adults: a 14 year prospective, longitudinal study. Arthritis Res Ther 2005;7:R1263-70.

9. Bravata DM, Smith-Spangler C, Sundaram V, Gienger $\mathrm{AL}$, Lin N, Lewis R, et al. Using pedometers to increase physical activity and improve health: a systematic review. JAMA 2007;298:2296-304.
10. Hirsch JA, Moore KA, Clarke PJ, Rodriguez DA, Evenson KR, Brines SJ, et al. Changes in the built environment and changes in the amount of walking over time: longitudinal results from the multi-ethnic study of atherosclerosis. Am J Epidemiol 2014;180:799-809.

11. Yamanouchi K, Shinozaki T, Chikada K, Nishikawa T, Ito $\mathrm{K}$, Shimizu S, et al. Daily walking combined with diet therapy is a useful means for obese NIDDM patients not only to reduce body weight but also to improve insulin sensitivity. Diabetes Care 1995;18:775-8.

12. Studenski S, Perera S, Patel K, Rosano C, Faulkner $\mathrm{K}$, Inzitari $\mathrm{M}$, et al. Gait speed and survival in older adults. JAMA 2011;305:50-8.

13. Guralnik JM, Ferrucci L, Pieper CF, Leveille SG, Markides KS, Ostir GV, et al. Lower extremity function and subsequent disability: consistency across studies, predictive models, and value of gait speed alone compared with the short physical performance battery. J Gerontol A Biol Sci Med Sci 2000;55:M221-31.

14. Montesi L, Moscatiello S, Malavolti M, Marzocchi R, Marchesini G. Physical activity for the prevention and treatment of metabolic disorders. Intern Emerg Med 2013;8:655-66.

15. Cruz-Jentoft AJ, Baeyens JP, Bauer JM, Boirie Y, Cederholm T, Landi F, et al. Sarcopenia: European consensus on definition and diagnosis: Report of the European Working Group on Sarcopenia in Older People. Age Ageing 2010;39:412-23.

16. Andersson GB. Epidemiological features of chronic low-back pain. Lancet 1999;354:581-5.

17. Luo X, Pietrobon R, Sun SX, Liu GG, Hey L. Estimates and patterns of direct health care expenditures among individuals with back pain in the United States. Spine (Phila Pa 1976) 2004;29:79-86.

18. Balague F, Mannion AF, Pellise F, Cedraschi C. Nonspecific low back pain. Lancet 2012;379:482-91.

19. Walker BF. The prevalence of low back pain: a systematic review of the literature from 1966 to 1998. J Spinal Disord 2000;13:205-17.

20. Koes BW, van Tulder MW, Ostelo R, Kim Burton A, Waddell G. Clinical guidelines for the management of low back pain in primary care: an international comparison. Spine (Phila Pa 1976) 2001;26:2504-13; discussion 2513-4.

21. Hayden JA, van Tulder MW, Tomlinson G. Systematic review: strategies for using exercise therapy to im- 
prove outcomes in chronic low back pain. Ann Intern Med 2005;142:776-85.

22. Lee S, Kim TN, Kim SH. Sarcopenic obesity is more closely associated with knee osteoarthritis than is nonsarcopenic obesity: a cross-sectional study. Arthritis Rheum 2012;64:3947-54.

23. An R, Burd NA. Change in daily energy intake associated with pairwise compositional change in carbohydrate, fat and protein intake among US adults, 19992010. Public Health Nutr 2015;18:1343-52.

24. Chun MY. Validity and reliability of korean version of international physical activity questionnaire short form in the elderly. Korean J Fam Med 2012;33:144-51.

25. EuroQol Group. EuroQol: a new facility for the measurement of health-related quality of life. Health Policy 1990;16:199-208.

26. Brooks R. EuroQol: the current state of play. Health Policy 1996;37:53-72.

27. Shiri R, Solovieva S, Husgafvel-Pursiainen K, Telama $\mathrm{R}$, Yang X, Viikari J, et al. The role of obesity and physical activity in non-specific and radiating low back pain: the Young Finns study. Semin Arthritis Rheum 2013;42:640-50.

28. Sitthipornvorakul E, Janwantanakul P, Purepong N, Pensri P, van der Beek AJ. The association between physical activity and neck and low back pain: a systematic review. Eur Spine J 2011;20:677-89.

29. Hendrick P, Te Wake AM, Tikkisetty AS, Wulff L, Yap C,
Milosavljevic S. The effectiveness of walking as an intervention for low back pain: a systematic review. Eur Spine J 2010;19:1613-20.

30. Sculco AD, Paup DC, Fernhall B, Sculco MJ. Effects of aerobic exercise on low back pain patients in treatment. Spine J 2001;1:95-101.

31. Krein SL, Kadri R, Hughes M, Kerr EA, Piette JD, Holleman $\mathrm{R}$, et al. Pedometer-based internet-mediated intervention for adults with chronic low back pain: randomized controlled trial. J Med Internet Res 2013; 15:e181.

32. Torstensen TA, Ljunggren AE, Meen HD, Odland E, Mowinckel P, Geijerstam S. Efficiency and costs of medical exercise therapy, conventional physiotherapy, and self-exercise in patients with chronic low back pain. A pragmatic, randomized, single-blinded, controlled trial with 1-year follow-up. Spine (Phila Pa 1976) 1998;23:2616-24.

33. Huang YP, Bruijn SM, Lin JH, Meijer OG, Wu WH, Abbasi-Bafghi $\mathrm{H}$, et al. Gait adaptations in low back pain patients with lumbar disc herniation: trunk coordination and arm swing. Eur Spine J 2011;20:491-9.

34. Lamoth CJ, Daffertshofer A, Meijer OG, Beek PJ. How do persons with chronic low back pain speed up and slow down? Trunk-pelvis coordination and lumbar erector spinae activity during gait. Gait Posture 2006; 23:230-9. 